\title{
Effect of Larval Swimming Duration on Growth and Reproduction of Bugula neritina (Bryozoa) Under Field Conditions
}

\author{
DEAN E. WENDT \\ Department of Organismic and Evolutionary Biology, Harvard University, \\ Cambridge, Massachusetts 02138
}

\begin{abstract}
A growing body of evidence indicates that even subtle events occurring during one portion of an animal's life cycle can have detrimental, and in some cases, lasting effects on later stages. Using a laboratoryfield transplant design, postmetamorphic costs associated with the duration of larval swimming were investigated in the bryozoan Bugula neritina. Larvae were induced to metamorphose in the laboratory after swimming for either less than $1 \mathrm{~h}$ or between 23 and $24 \mathrm{~h}$; colonies that developed from these two groups of larvae are referred to hereafter as " 1 -h colonies" and "24-h colonies," respectively. After completing metamorphosis, individuals were transplanted to the field, where rates of growth and reproduction were monitored. In a study of the interaction between colony orientation (up or down) and larval swimming duration, both factors significantly affected the number of autozooids produced. For example, 14 days after metamorphosis, 1-h colonies facing up were approximately $40 \%$ smaller than 1 -h colonies facing down. In another study, the effects of larval swimming duration, orientation, and a neighboring conspecific colony on growth and reproduction were examined. In this experiment, proximity to a conspecific colony and orientation did not significantly affect growth or fecundity, whereas increased larval swimming duration significantly reduced both. For example, 14 days after metamorphosis, the 24$\mathrm{h}$ colonies were $35 \%$ smaller than 1 -h colonies. Furthermore, from the time metamorphosis was initiated, the onset of reproduction was delayed by about 1.5 days in 24-h colonies when compared to 1-h colonies; and a slight delay ( $c a .1$ day) was associated with proximity of a
\end{abstract}

developing conspecific in 1-h and $24-\mathrm{h}$ colonies. In addition, 17 days after metamorphosis, 24-h colonies had about half as many brood chambers (an index of fecundity) as 1-h colonies. Costs associated with increasing the larval swimming phase by only $24 \mathrm{~h}$ are significant in postmetamorphic individuals, and they clearly compromise colony fitness.

\section{Introduction}

Possession of a larval stage is common in a wide range of animals, including many fish, amphibians, and both terrestrial and aquatic invertebrates. Occurrence across such an array of taxa suggests that some benefits are associated with a motile larval stage (Strathmann, 1993; Havenhand, 1995; Wray, 1995). For marine invertebrates, a major benefit is dispersal ability, which, for cxamplc, reduces parent-offspring competition and facilitates the recolonization of disturbed habitats. In species with sedentary or sessile adults, larvae help to increase gene flow between geographically separated populations and extend species' ranges. However, there are also costs associated with a free-living larval stage (Pechenik, 1990). These costs can be lethal (advection from suitable habitats, predation, and loss of metamorphic competence), or sublethal (slower growth after metamorphosis and delayed onset of reproduction). Thus, by severely limiting dispersal, these costs probably contribute to the speciation of marine invertebrates with aplanktotrophic larvae (see Wendt, 1996, for a discussion of this term).

Models used to examine the life-history strategies and population dynamics of marine invertebrates have focused on the lethal costs of dispersal (e.g., Vance, 1973; Strathmann, 1985; Roughgarden et al., 1988); the suble- 
thal costs have been largely overlooked. Recent work demonstrates that sublethal effects can dramatically influence juvenile growth and survival under laboratory conditions (Woollacott et al., 1989; Pechenik and Cerulli, 1991; Pechenik et al., 1993; Wendt, 1996). This study assesses the costs of larval swimming duration on growth and reproduction under field conditions in the cheilostome bryozoan Bugula neritina.

Larvae of marine invertebrates commonly metamorphose in response to cues indicative of a favorable habitat for the adult (Scheltema, 1974; Hadfield, 1978; Crisp, 1984; Chia, 1989; Pawlik, 1992). Once physiologically competent to metamorphose, a larva can remain in the swimming phase because it has not encountered a suitablc cue to trigger metamorphosis or because it does not respond to the normal metamorphic cue as a consequence of additional factors. For example, Young and Chia (1981) demonstrated that competent larvae of Bugula pacifica delay metamorphosis in the presence of extracts of the compound ascidian Diplosoma macdonaldi, a dominant competitor. An extended larval swimming period occurs when an individual becomes physiologically capable of responding to cues that elicit metamorphosis, but instead continues swimming. The benefit of remaining in the swimming phase is the increased likelihood of synchronizing the onset of metamorphosis with encountering a favorable adult site. On the other hand, the longer a larva swims the greater its exposure to the potentially lethal and sublethal effects of a planktonic existence (Rumrill, 1990; Morgan, 1995).

The adverse effects of an extended larval swimming phase are well documented in laboratory studies of marine invertebrates. Increasing larval swimming time in the polychaete Capitella sp. I significantly decreased postsettlement survivorship from $100 \%$ to $12.5 \%$ over $216 \mathrm{~h}$ of larval swimming (Pechenik and Cerulli, 1991). In bryozoans identified as Bugula spp., the ability to initiate and complete metamorphosis was inversely proportional to larval swimming duration (Woollacott et al., 1989; Hunter and Fusetani, 1996; Wendt, 1996). Furthermore, a loss of metamorphic competence was observed after 24 $\mathrm{h}$ of larval swimming in Celleporella hyalina, another cheilostome bryozoan (Orellana and Cancino, 1991).

The size of postmetamorphic individuals is affected by the duration of larval swimming. Unusually small ancestrulae developed from larvae of the bryozoan Hippodiplosia insculpta that swam for longer than $6 \mathrm{~h}$ (Nielson, 1981). Wendt (1996) quantitatively extended Nielson's qualitative observations on $H$. insculpta to $B$. neritina, showing that ancestrulae developed from larvae that swam for $28 \mathrm{~h}$ had lophophores (the feeding apparatus) $25 \%$ smaller in height, $40 \%$ smaller in surface area, and $50 \%$ smaller in volume, compared to ancestrulae that developed from larvae induced to metamorphose within $1 \mathrm{~h}$ of release.
Only short-term effects of increased larval swimming duration on growth have been assessed. For example, in 12 out of 14 cases, Woollacott et al. (1989) found that after $11 \mathrm{~h}$ of swimming, larvae of $B$. stolonifera developed into juveniles that grew significantly slower than juveniles from larvae that swam for only $6 \mathrm{~h}$. Likewise, for the barnacle Balanus amphitrite, increasing the swimming period of cyprids for 3-5 days depressed juvenile growth rate compared to controls (Pechenik et al., 1993). Longterm effects on growth and reproduction have not been explored.

Effects associated with increased swimming duration are common, but not universal. For example, Highsmith and Emlet (1986) found no significant correlation between "delay time" and juvenile growth rate in the sand dollar Echinarachnius parma, which has planktotrophic larvae. In the gastropod Crepidula fornicata, which also has a planktotrophic larva, no significant differences were observed in average rates of survival, feeding, respiration, or growth between juveniles that were induced to metamorphose shortly after attaining competence and those that kept swimming until metamorphosis occurred spontaneously (Pechenik and Eyster, 1989).

In general, the adverse effects associated with larval swimming duration are common in species with aplanktotrophic larvae, whereas species with planktotrophic larvae typically are buffered from these costs. Information on the long-term effects of larval swimming duration on adults are confined to a single laboratory study (Pechenik and Cerulli, 1991) of a polychaete. No study has yet evaluated the performance of individuals in the field. I assess, under field conditions, the long-term costs of increasing larval swimming duration on colony growth and reproduction of Bugula neritina. In addition, I investigate the effects of colony orientation and intraspecific competition in relation to larval swimming duration.

\section{Materials and Methods}

\section{Collection of specimens}

Gravid colonies of Bugula neritina were collected from the undersides of floating docks near the Smithsonian Marinc Station at Link Port in Fort Pierce, Florida, during February and March 1997. Colonies were maintained in light-tight, flow-through plastic containers. Natural seawater from the Indian River (salinity $c a .32 \mathrm{ppt}$ ) was continuously pumped through the containers, providing the colonies with ambient levels of food and oxygen.

\section{Larval release}

Larvae were obtained from several colonies to foster genetically heterogeneous populations for experiments, and larvae used in experiments were obtained only from 
parent colonies kept in the laboratory less than 5 days. There were no qualitative differences between colonies kept in the light-tight boxes for 1 day and those kept for 5 days; in fact, colonies stayed healthy under these conditions for several weeks after the experiments. Colonies were removed from the light-tight containers, placed in glass bowls with 1.01 of seawater, and exposed to fluorescent light. Larvae appeared within 10 min of illumination, and release was complete by $1 \mathrm{~h}$. As B. neritina larvae are positively phototactic on release, they aggregated at the illuminated side of the dishes, a behavior that facilitated their collection.

\section{Larval swimming}

Following release, larvae were transferred to an autoclaved, 1.5-l glass finger bowl containing about $1.0 \mathrm{l}$ of $0.2-\mu \mathrm{m}$ filtered seawater. Larvae were prevented from initiating metamorphosis by continuous exposure to bright, fluorescent illumination accompanied by stirring (Wendt, 1996). The bowl was placed on an acrylic plastic table to reduce UV exposure and illuminated from below with four 20-W, 24-in. full-spectrum DayCycle lamps. An additional two 20-W, 24-in. fluorescent lamps were used to increase the overall lighted area. Pieces of aluminum foil were placed around the finger bowl to create a constant reflection and constant levels of illumination from all directions. Illumination levels ranged from 130 to $170 \mu \mathrm{E} \mathrm{m}^{-2} \mathrm{~s}^{-1}$. Fans were installed under the acrylic table to maintain ambient room temperatures $\left(\mathrm{ca} .22^{\circ} \mathrm{C}\right)$ during larval swimming.

\section{Metamorphosis}

Groups of larvae were induced to metamorphose in small polystyrene dishes by adding $10 \mathrm{mM}$ excess $\mathrm{KCl}$ to the seawater (Wendt and Woollacott, 1995). Metamorphosis is the time from eversion of the larval metasomal sac to eversion of the lophophore of the ancestrular polypide. To synchronize completion of metamorphosis for 1-h and 24-h individuals, larvae released on two consecutive days were used for each experiment. Those released on the first day were kept swimming for $24 \mathrm{~h}$ before metamorphosis was initiated. On the second day, the same adult colonies were used for another release of larvae. This release was $6 \mathrm{~h}$ later than on the previous day to allow for the increased time individuals take to metamorphose after swimming for $24 \mathrm{~h}$ (Wendt, 1996). This release schedule ensured that $1-\mathrm{h}$ and $24-\mathrm{h}$ individuals finished metamorphosis at about the same time ( $c a .48 \mathrm{~h}$ ). Spontaneous metamorphosis was generally rare and occurred at very low levels. If more than $5 \%$ of the larvae metamorphosed during larval swimming, the experiment was aborted.

Growth in these experiments was estimated by counting the number of autozooids and bifurcations in a colony. Bryozoans grow by asexual reproduction of modular units, zooids, from a sexually produced individual, the ancestrula. Zooids are connected to one another by a strand of tissue, the funiculus. Most generally there are two types of zooids: autozooids, which are present in all species, are specialized for feeding and digestion; heterozooids, which are not found in all species, function in defense, attachment, and reproduction. In $B$. neritina, brood chambers are the sole type of heterozooid. Thus, the number of autozooids is a good estimator of colony growth and has an advantage over dry weight or colony length in that it can be determined nondestructively over many days in the samc individuals.

\section{Effect of larval swimming duration and colony orientation on adult growth}

Larvae were released and metamorphosed as described above. Two polystyrene dishes were attached with lowtemperature hot glue to a clear acrylic plastic plate. Three to five larvae were pipetted into dishes to ensure successful metamorphosis of at least one. On completion of metamorphosis, all but a single individual were removed and the sides of the dish were trimmed away so that only the flat bottom portion remained. Each replicate consisted of two plates, each with two dishes and a total of four individuals: colony orientation was up (high siltation) or down (low siltation), and each plate had a 1-h and a 24-h individual (Fig. 1). The relative positions of the individuals were changed between replicates so as to nullify any micro-environmental effects associated with the plates. The replicate plates were then attached to nylon

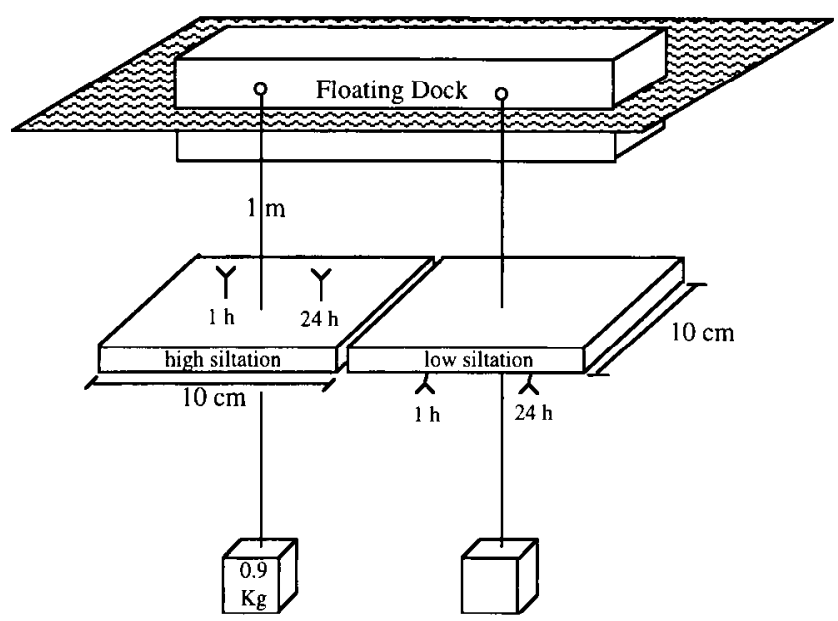

Figure 1. Experimental apparatus for assessing the effect of colony orientation and swimming duration on growth. See text for details on the placement of ancestrulae $(\mathbf{Y})$. The colonies were placed far enough apart so that no competition for food and space occurred. Colonies grew for 14 days and then were returned to the laboratory for scoring. 
line at intervals of about $35 \mathrm{~cm}$ and suspended from floating docks. Lead ballasts weighing $0.90 \mathrm{~kg}$ were hung $0.5 \mathrm{~m}$ below the plates to keep them level, and the plates were submerged about $1 \mathrm{~m}$ below the surface. A rain gauge modified to serve as a sediment trap was submerged at the same level as the plates to provide a rough estimate of the amount of sediment accumulation over the course of the experiment. After 14 days, the plates were returned to the laboratory and the number of autozooids and bifurcations counted for each colony. Each condition started with 18 replicates, totaling 72 individuals.

Effect of larval swimming duration, orientation, and the presence of a conspecific colony on growth and reproduction

Larvae were released and metamorphosed as described above. About 50 individuals were pipetted into polystyrene dishes and allowed to metamorphose. The dishes were carved into thin strips such that each strip had a newly metamorphosed individual on its end (Fig. 2). The experimental apparatus was a plastic box that contained "lanes" with walls made of dense, chemically inert foam. Tiny slits were made in the foam, which allowed one end of the strip to be inserted in the wall of the lane. Another individual was placed in a slit directly opposite the first, so that the individuals shared space in the center of a lane. For each apparatus there were eight individuals in a total of four lanes. The individuals were either in the presence or absence of competition with a neighboring conspecific (i.e., with a conspecific in a slit directly across the lane facing the same direction) and were either 1-h or 24-h colonies. Another factor in this experiment was orientation (up or down; Fig. 2). However, orientation in this experiment did not expose colonies to different amounts of siltation, as the apparatus was designed to shield colonies from the downward flux of particulate matter. After metamorphosis (ca. $48 \mathrm{~h}$ ), individuals were arranged in blocks and transplanted to the field.

Each apparatus was removed daily and the numbers of autozooids, bifurcations, and brood chambers were counted for each colony. Because the blocks were designed to hold a small volume of seawater, colonies were never exposed to the air during this process. As the colonies grew it became difficult to score all parameters in a single day, so only bifurcations and brood chambers were counted for all colonies after day 12. The number of autozooids was counted for replicate boxes $1-15$ on day 13 and for boxes $16-30$ on day 14 . Due to time constraints, autozooids were not counted after day 14. The experiment was ended on day 17 , because the largest colonies began to overgrow the apparatus, potentially introducing additional effects. Analysis of variance (ANOVA) was applied to zooid data from day 12 and

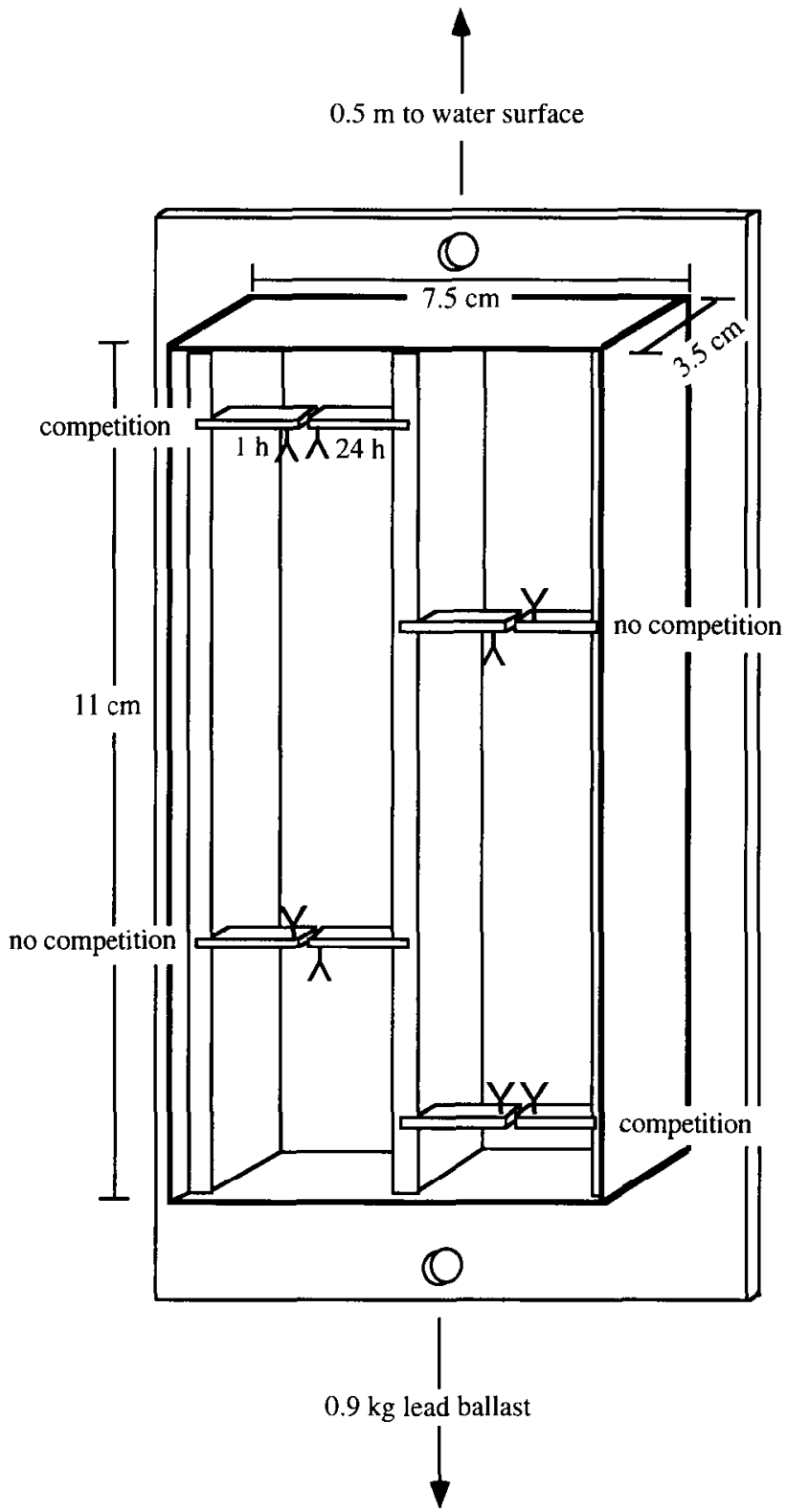

Figure 2. Experimental apparatus for assessing the effect of competition and swimming duration on growth and reproduction. See text for details on placement of ancestrulae $(\mathbf{Y})$.

bifurcation and brood chamber data from day 17; these were the last days the respective data were collected for all colonies.

\section{Data analysis}

The data were not significantly different from a normal distribution, and a square root transformation was used to remove heteroscedasticity. The data were back-transformed for presentation in graphs and text. Since all factors were fixed, a Model I ANOVA was used. For the 
experiment on swimming time and colony orientation a 2-way factorial ANOVA was used to identify heterogeneity of variances within the data sets. The main effects were swimming duration and orientation. For the experiment on competition and swimming duration a 3-way ANOVA was used and the main effects were swimming duration, presence of a conspecific, and orientation. Nonlinear regressions were done in SYSTAT using simple and general allometry models (Ebert and Russell, 1994).

\section{Results}

Increased duration of larval swimming significantly reduced growth and reproduction in both experiments with $B$. neritina. Colony orientation, when designed to expose colonies to different amounts of siltation pressure, also affected growth: colonies facing down were significantly larger than those facing up. The proximity of a conspecific (i.e., intraspecific competition), did not significantly affect growth, although it slightly delayed the onset of reproduction. Growth between experiments cannot be compared since there was a temperature difference of more than $5^{\circ} \mathrm{C}$ between the first and second experiments. On average, colonies grew faster under warmer conditions.

\section{Effect of larval swimming duration and colony orientation on growth}

During the 14 days of this experiment, approximately $0.2 \mathrm{~cm}$ of sediment accumulated in the trap and on the surfaces of the plates. Larval swimming duration and col- ony orientation significantly affected growth as measured by the number of autozooids and bifurcations in a colony (Fig. 3A, B; Table I). In no case was the interaction between swimming duration and orientation significant ( $P=0.53$ for zooid number and $P=0.65$ for bifurcations). On average, 1-h colonies facing down (light siltation load) had twice the number of autozooids and bifurcations as 24-h hour colonies facing up; whereas 1-h colonies facing up had almost the same number of autozooids and bifurcations as 24-h colonies facing down (Fig. 3). Reproduction of colonies did not occur at levels high enough to warrant statistical analysis.

Effect of larval swimming duration, colony orientation, and the presence of a conspecific on growth and reproduction

Neither orientation nor development next to a conspecific colony significantly affected growth and reproductive output as determined by ANOVA (Table II). Orientation did not expose animals to different amounts of siltation in this experiment, because the apparatus was shielded from the downward flux of particulate matter. Colony proximity appears to have some effect on the onset of reproduction (Fig. 4). Among 1-h colonies, those in the presence of a conspecific reached $50 \%$ reproduction $12 \mathrm{~h}$ later than those without a conspecific neighbor. Likewise, in the absence of a conspecific neighbor, 24-h colonies reached $50 \%$ reproduction more than $31 \mathrm{~h}$ later than 1 -h colonies (Fig. 4). On average, both the presence of a
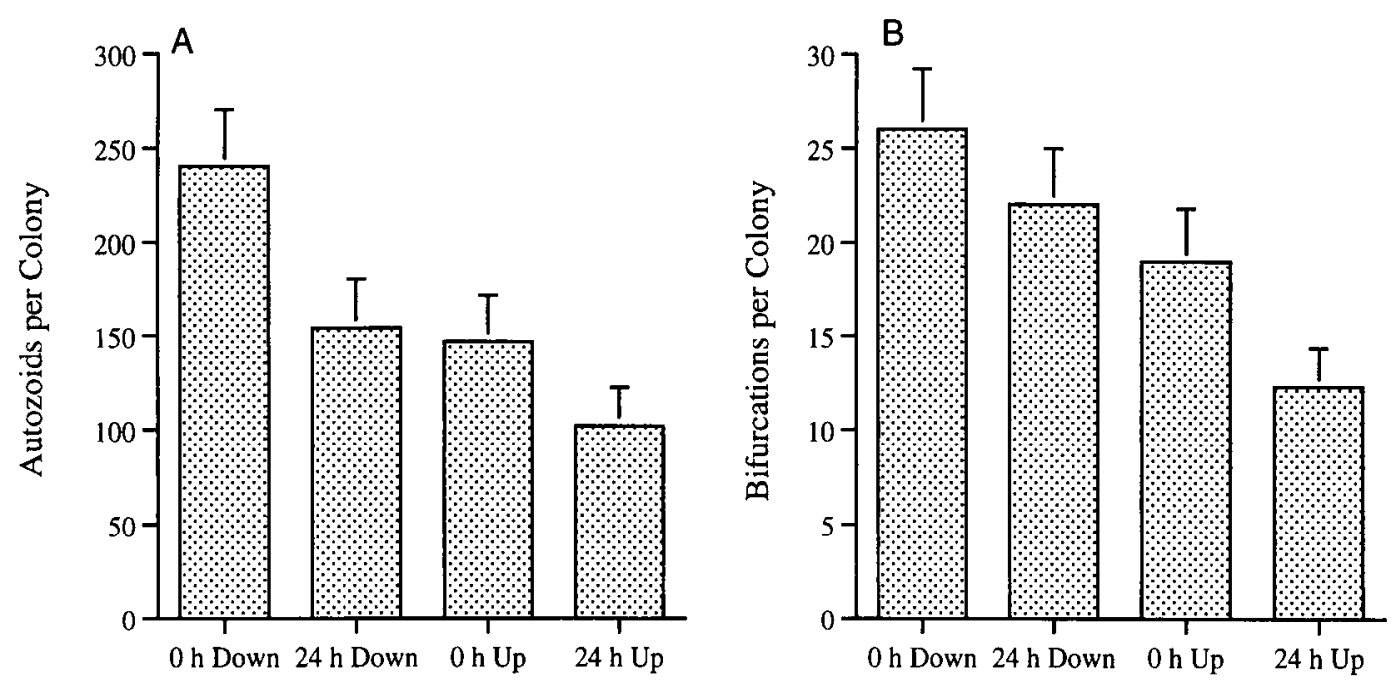

Condition

Figure 3. Number of autozooids and bifurcations in 1-h and 24-h colonies, 14 days after metamorphosis. Colonies were oriented up ("high siltation") or down ("low siltation"). Error bars $=95 \%$ confidence interval; $n=c a$. 50 colonies. 
Table I

Results of two-way factorial ANOVA for the effect of larval swimming duration and colony orientation (up or down) on the number of zooids and bifurcations in Bugula neritina colonies ( $\mathrm{n}=53$ colonies)

\begin{tabular}{|c|c|c|c|c|c|c|}
\hline Measurement & Source of variation & df & SS & MS & $F_{\mathrm{s}}$ & $P$ value \\
\hline \multirow[t]{4}{*}{ Bifurcations } & Swimming duration & 1 & 5.19 & 5.19 & 3.74 & 0.05 \\
\hline & Orientation & 1 & 11.5 & 11.5 & 8.28 & 0.006 \\
\hline & Interaction & 1 & 0.55 & 0.55 & 0.40 & 0.53 \\
\hline & Residual & 49 & 68.1 & 1.39 & - & - \\
\hline \multirow[t]{4}{*}{ Autozooids } & Swimming duration & 1 & 88.7 & 88.7 & 5.11 & 0.02 \\
\hline & Orientation & 1 & 108 & 108 & 6.22 & 0.01 \\
\hline & Interaction & 1 & 3.56 & 3.56 & 0.21 & 0.65 \\
\hline & Residual & 52 & 903 & 17.4 & - & - \\
\hline
\end{tabular}

conspecific colony and increased duration of larval swimming delayed the onset of reproduction; differences of less than $12 \mathrm{~h}$ cannot be resolved.

Longer larval swimming leads to reduced growth and reproductive output (Table II; Figs. 5, 6, and 7). For example, 14 days after metamorphosis the average number of autozoids was $113 \pm 7(n=50$; mean $\pm 95 \%$ confidence) for 1-h colonies, compared to $74 \pm 6(n=49)$, for 24 -h colonies. However, the slopes of the regression lines for autozooid number as a function of days after metamorphosis were statistically indistinguishable; an indication that both groups of colonies were growing at about the same rates, despitc differences in the absolute number of autozooids at day 14 (Fig. 5). The number of brood chambers, a measure of reproductive output, was significantly lower in 24-h colonies $(P<0.001)$. The average number of brood chambers was $149 \pm 19(n-94 ;$ mean $\pm 95 \%$ confidence $)$ for 1-h colonies and $76 \pm 11(n=93)$ for $24-\mathrm{h}$ colonies Thus, 17 days after metamorphosis, 1-h colonies had, on average, more than twice the number of brood chambers as did 24-h colonies. Furthermore, unlike the rate of production of new autozooids, which was similar in 1-h and 24-h colonies very soon after metamorphosis, the rate of brood-chamber production was significantly less in 24-h colonies for the duration of the experiment (Fig. 7). Similar trends were observed in bifurcations (Fig. 6).

The only significant interaction between main factors was between colony orientation and proximity of a conspecific $(F=7.6, P=0.006$ for brood chambers; $F=$ $6.5, P=0.01$ for autozooids).

\section{Discussion}

Most empirical evidence that nonlethal larval experiences have long-term effects comes from observations

Table II

Results of three-way factorial ANOVA for the effect of larval swimming duration, colony orientation (up or down), and competition on the number of zooids, bifurcations, and brood chambers in Bugula neritina colonies $(\mathrm{n}=180$ colonies $)$

\begin{tabular}{|c|c|c|c|c|c|c|}
\hline Measurement & Source of variation & df & SS & MS & $F_{\mathrm{s}}$ & $P$ value \\
\hline \multirow[t]{5}{*}{ Bifurcations } & Swimming duration & 1 & 24.1 & 24.1 & 23.8 & 0.0001 \\
\hline & Competition & 1 & 1.83 & 1.83 & 1.81 & 0.18 \\
\hline & Orientation & 1 & 0.16 & 0.16 & 0.16 & 0.69 \\
\hline & Interactions & 4 & 3.03 & 0.76 & 0.08 & $>0.5$ \\
\hline & Residual & 180 & 181 & 1.01 & - & - \\
\hline \multirow[t]{5}{*}{ Autozooids } & Swimming duration & 1 & 42.8 & 42.8 & 30.3 & 0.0001 \\
\hline & Competition & 1 & 0.46 & 0.46 & 0.32 & 0.57 \\
\hline & Orientation & 1 & 0.62 & 0.62 & 0.44 & 0.51 \\
\hline & Interactions* & 4 & 2.58 & 0.64 & 0.46 & $>0.5$ \\
\hline & Residual & 179 & 252 & 1.41 & - & - \\
\hline \multirow[t]{5}{*}{ Brood chambers } & Swimming duration & 1 & 584 & 584 & 33.8 & 0.0001 \\
\hline & Competition & 1 & 1.51 & 1.51 & 0.09 & 0.77 \\
\hline & Orientation & 1 & 2.49 & 2.49 & 0.14 & 0.71 \\
\hline & Interactions* & 4 & 167 & 41.7 & 2.43 & 0.11 \\
\hline & Residual & 178 & 3100 & 17.3 & - & - \\
\hline
\end{tabular}

For clarity, the interactions of main effects were collapsed into a single interaction term.

* There was a significant interaction between orientation and competition; see Discussion for an examination of this outcome. 


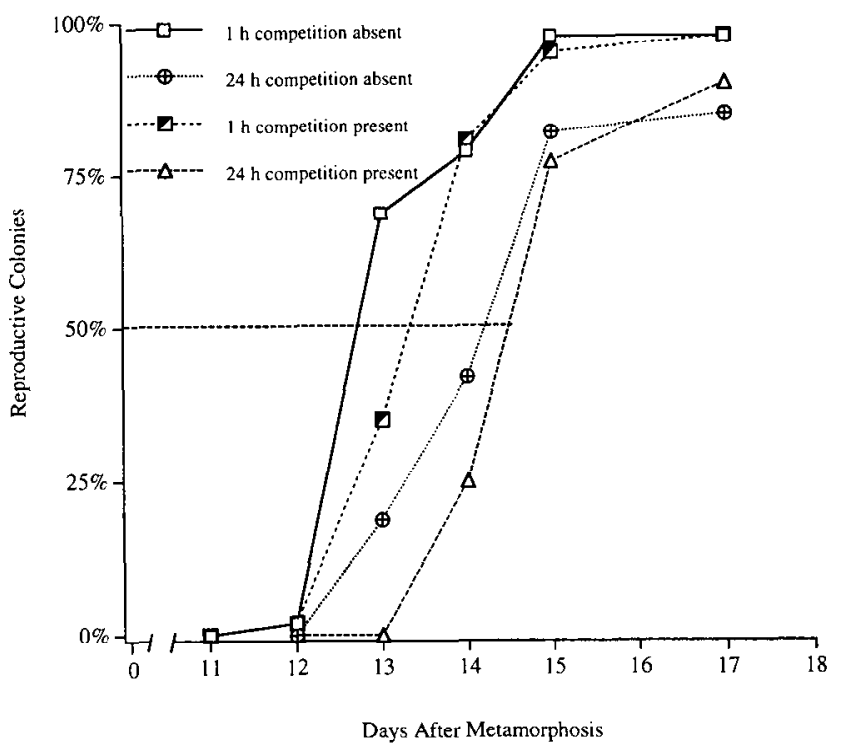

Figure 4. Onset of reproduction in Bugula neritina as a function of larval swimming duration, competition, and time after metamorphosis. $n=40-50$ colonies for each curve.

on marine invertebrates with aplanktotrophic larvae. The influence of such experiences on postmetamorphic performance is not restricted to marine invertebrates, however. For example, the feeding history of larval reef fish affects the average diameter of tail muscle fibers, average size at settlement, and average juvenile feeding rates (McCor-

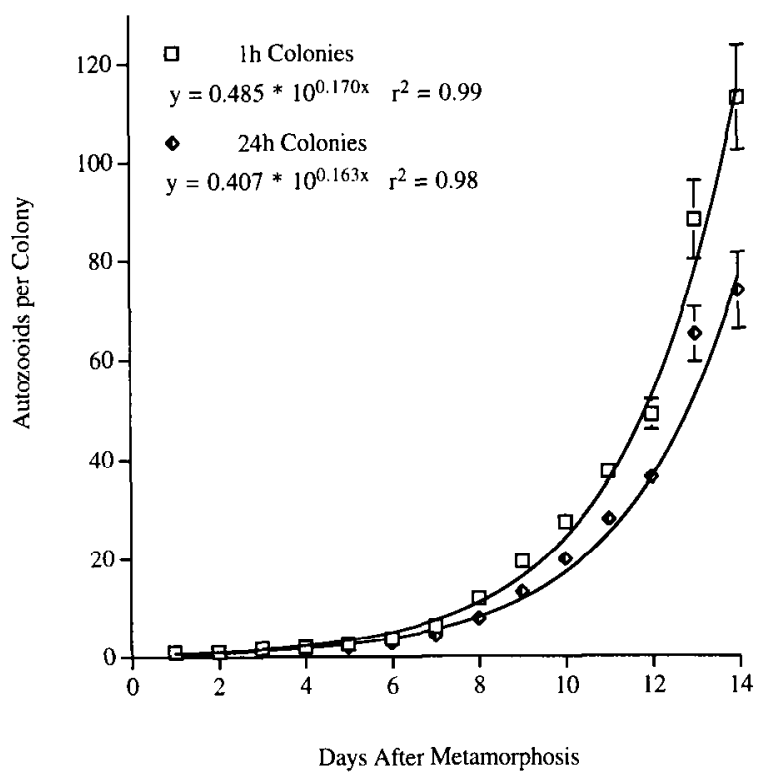

Figure 5. Mean number of autozooids as a function of larval swimming duration and time after metamorphosis in Bugula neritina. Error bars $=95 \%$ confidence interval of the means. $n=c a$. 90 colonies for each curve, and all nonsignificant data were pooled. Regressions were calculated using all zero values for $y$.

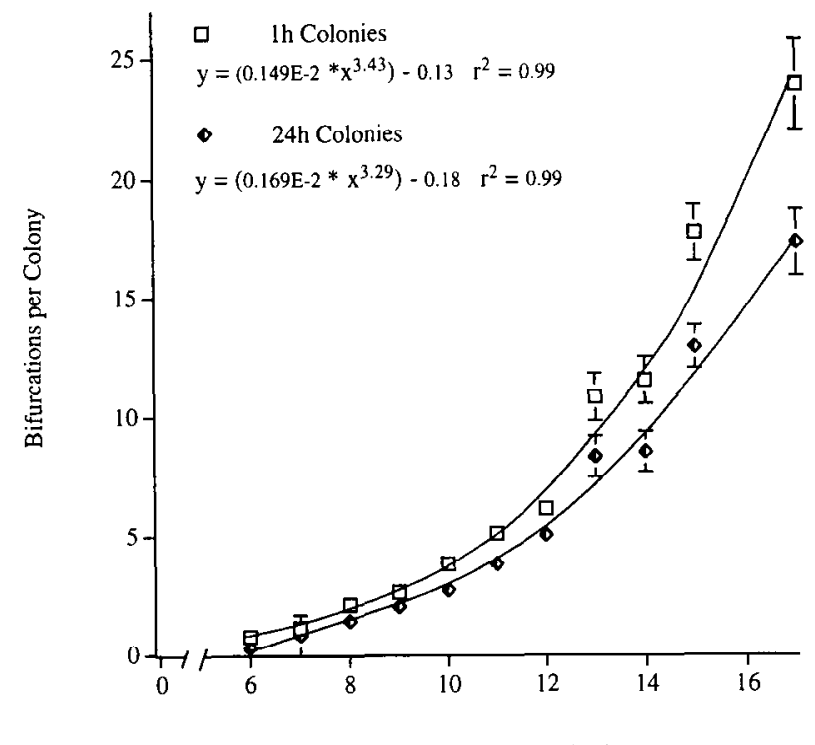

Days After Metamorphosis

Figure 6. Mean number of bifurcations as a function of larval swimming duration and time after metamorphosis in Bugula neritina. Error bars $=95 \%$ confidence interval of the means. $n=c a$. 90 colonies for each curve, and all nonsignificant data were pooled. Regressions were calculated using all zero values for $y$.

mick and Molony, 1992). In amphibians, food deprivation at different periods of tadpole ontogeny can precipitate metamorphosis at smaller sizes (Audo et al., 1995). In insects, the reproductive fitness of the adult female flesh

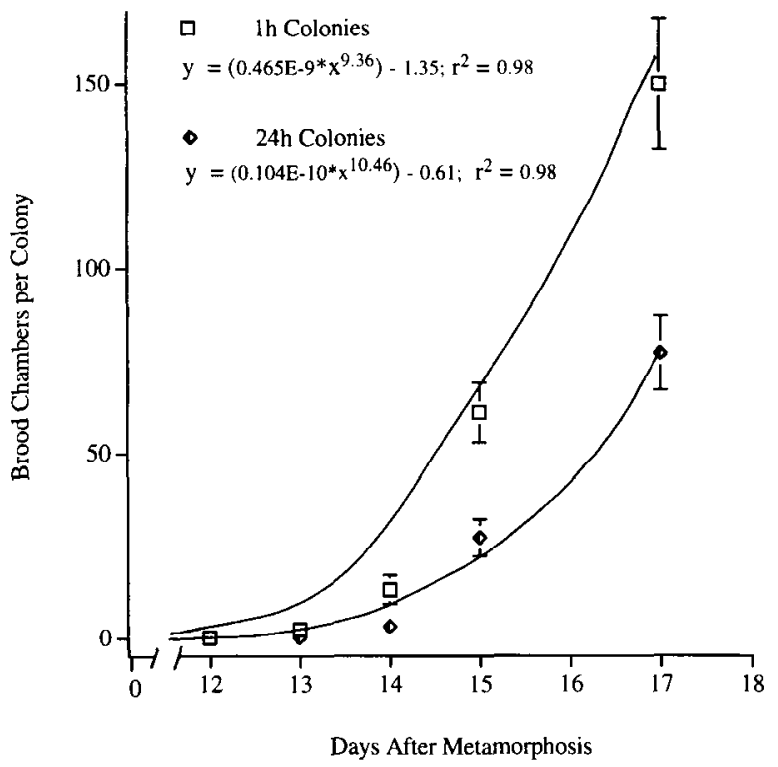

Figure 7. Mean number of brood chambers as a function of larval swimming duration and time after metamorphosis in Bugula neritina colonies. Error bars $=95 \%$ confidence interval of the means. $n=c a$. 90 colonies for each curve, and all nonsignificant data were pooled. Regressions were calculated using all zero values for $y$. 
fly is inversely correlated with the amount of time the larva spends in diapause (Denlinger, 1981).

\section{Effect of larval swimming duration on growth and reproduction}

In both the siltation and the competition experiments, a 24-h increase in the larval swimming period significantly reduced growth and reproduction compared to $1-\mathrm{h}$ colonies (Tables I and II). Since growth in $B$. neritina is an exponential process, small differences during early colony development will translate into large differences in colony size (Figs. 5 and 6). On average, 24-h colonies had half as many autozooids, bifurcations, and brood chambers as did 1-h colonies over the same time of development. The observed difference is not a result of 24-h colonies finishing metamorphosis $23 \mathrm{~h}$ later than $1-\mathrm{h}$ colonies, as experiments were designed so that both groups of animals finished metamorphosis and began feeding at nearly the same time. Thus, the lower values observed for 24 -h colonies cannot be attributed to a shorter period of postmetamorphic development - in fact, 24-h larvae take an additional 6-8 h to metamorphose (Wendt, 1996). Overall, then, the differences observed between $1-h$ and $24-h$ colonies are conservative.

Because 24-h colonies initially grow more slowly, they will always have fewer autozooids, bifurcations, and brood chambers at a given point in time and, assuming similar growth potentials, they will never "catch up" to their 1-h counterparts. But is there a point at which the two groups have equal rates of growth or reproduction? For growth rate, as measured by the number of autozooids, this happens several days after metamorphosis when the slope of the regression lines are virtually identical (Fig. 5). For reproduction, however, the slopes of the regression lines appear to be different throughout the duration of the experiment (Fig. 6), indicating that, 17 days after metamorphosis, 24-h colonies have not produced brood chambers at the same rate as 1 -h colonies. Considering that colonies in the Indian River in the vicinity of the Smithsonian Marine Station at Link Port persist in the field for 5 or 6 weeks at most (L. J. Walters, pers. comm.; DEW, pers. observ.), the rate of reproductive output would be severely compromised as the larval swimming phase increases.

\section{Effect of colony orientation on growth}

Orientation of developing colonies significantly affected growth in $B$. neritina (Table I; Fig. 3), presumably by influencing the amount of siltation the colonies encountered. Colonies on the upper surfaces of the plates, which experienced a higher concentration of silt particles, grew more slowly. The hypothesis that the additional particles interfered with feeding is supported by evidence from colonies of the intertidal bryozoan Flustrellidra hispida. In that species, the concentration of inorganic suspended particulate matter (i.e., silt) is inversely related to the number of autozooids actively feeding (Best and Thorpe, 1996). A colony with fewer feeding autozooids is likely to capture less food and consequently have less cncrgy available for growth and reproduction. Scdimentation has also been shown to be a significant source of mortality in newly settled solitary ascidians (Young and Chia, 1984).

That colonies on the undersides of surfaces grow significantly larger than those on the upper surfaces suggests that facing downward is beneficial. Many invertebrate larvae are known to settle and metamorphose in environments that favor the chances of adult survival (Olson, 1983; Young and Chia, 1985; Walters and Wethey, 1991; Walters, 1992; Hurlbut, 1993). In the field, $B$. neritina colonies are most often found growing on the undersides of objects and ledges. Whether this distribution is the result of larval behavior, differential postmetamorphic mortality, or some combination of the two has not been explicitly investigated. However, certain larval behaviors may, in part, account for the patterns observed in the field. Larvae of $B$. neritina settle preferentially on the undersides of plates in the field, and they also settle in shaded areas (Ryland, 1977; Table II). At the time of attachment, larvae settle such that the incipient zooid and the resultant colony face away from light (McDougall, 1943). Under natural conditions with light from above, the colony is oriented with its frontal surface and lophophore facing away from the water surface; thus, the colony is shielded from the downward flux of particulate matter. Not all behaviors produce this result, however. Colonies of $B$. avicularia and $B$. neritina show a positive phototropism (Aymes, 1956; Schneider, 1959), which, according to the results of the current study, would retard growth, since the colonies would grow frontal surface up.

Orientation did not significantly affect growth in the competition experiment, which is not surprising in that orientation in this experiment did not expose colonies to different amounts of siltation. All colonies were shielded from sedimentation, and no sediment accumulated on the surfaces where colonies were growing. One factor not controlled for in this experiment was UV radiation. Although UV light has the potential to affect growth, the overall exposure for any colony in the experiment was minimal because none of the replicates were ever exposed to direct sunlight.

\section{Effect of the presence of a conspecific colony on growth and reproduction}

The adjacency of a conspecific colony (i.e., a potential competitor) did not significantly affect growth and repro- 
duction (Table II). Either postmetamorphic competitive ability is not compromised by increased duration of larval swimming or the individuals did not experience a limiting resource and were not subjected, therefore, to a competitive situation. $\Lambda$ priori, the former reason appears less satisfactory given that lophophore size decreases significantly as a function of larval swimming duration (Wendt, 1996) and that smaller lophophores generate currents with lower velocities (Best and Thorpe, 1986). Both lophophore size and current velocity can influence interactions as colonies grow and compete for space and food (Buss, 1979). The more likely explanation is that individuals did not experience a limited supply of food. The effects of inter- and intraspecific competition in the context of increased duration of larval swimming remain unresolved.

\section{Interaction between orientation and competition}

In the competition experiment, neither competition nor orientation as main factors had a significant effect on growth and reproduction. However, there was a significant interaction between these factors $(F=7.6, P=0.006$ for brood chambers; $F=6.5, P=.01$ for autozooids), which suggests that some combination of orientation and competition may result in reduced growth and reproduction. Ad hoc analysis showed that in 4 out of 5 cases, individuals that faced competition and were oriented upward (i.e., had a light siltation load in this experiment) had, on average, fewer zooids, brood chambers, and bifurcations. This result indicates that competition and upward orientation acting individually were not strong enough factors to reduce growth and reproduction, but that in concert they may compromise colony fitness.

\section{Mechanisms of action}

The observed difference in the rates of autozooid budding is probably a result of a delay in the time to first bud, because the increased larval swimming period undoubtedly uses energy that would otherwise go to form the first autozooid. Any energetic deficiency of the ancestrula should not persist, however, so the growth rate should approach normal by the time the first several buds have formed. The difference in the quantity and production rate of brood chambers between 1-h and 24-h colonies is enigmatic. The difference is unlikely to result solely from the energetic deficiency caused by a lengthened period of larval swimming. One other mechanism that might play a part in producing these long-term effects is interspecific competition between bryozoans and stalked protozoans (e.g., Canchesium sp., Zoothanium sp., Vorticella sp.). Unfortunately it was impossible to cxclude these pervasive interspecific competitors, which colonized the surfaces of colonies. Consequently, all conditions had a background of interspecific competition and there could be some difference in interspecific competitive ability of 1-h and 24-h colonies. An alternative explanation suggested by Pechenik et al. (in press) is that ccrtain gene products transcribed early in development may be needed for organogenesis and that certain environmental stresses encountered in larval life may interfere with transcriptional or translational processes. Furthermore, it is well known that environmental stress can damage populations of cells and even entire organs during development. In any case, it seems that the effects observed in $B$. neritina may not be attributed entirely to energetic causes.

\section{Effect of larval dispersal ability on species evolution}

Taylor (1988) proposed that the major radiation of cheilostome bryozoans 150 million years ago was in part due to the evolution of nonfeeding larvae (like those of $B$. neritina), which severely limited the dispersal of these species. In general, species with this type of larva (shortlived, aplanktotrophic) have lower gene flow between subpopulations-and thus a greater subpopulation genetic structure-than species with long-lived, planktotrophic larvae (Palumbi, 1994). My results support Taylor's hypothesis by demonstrating that individuals of $B$. neritina (and probably of all bryozoans with aplanktotrophic larvae) incur substantial lethal and nonlethal costs after relatively short periods of larval swimming (hours to days). These costs limit the dispersal of bryozoans with aplanktotrophic larvae and may contribute significantly to subpopulation genetic structure. On evolutionary time scales, these costs and their consequences have probably played a central role in speciation within the Bryozoa.

\section{Acknowledgments}

I thank Sherry Reed, Hugh Reichardt, and Dr. Mary E. Rice, all of the Smithsonian Marine Station at Fort Pierce, Fort Pierce, Florida, for their assistance in carrying out this research. Colleen Cavanaugh, Peter Goss, Ed Seling, and Robert Woollacott (all of Harvard University) provided thoughtful discussions and comments which greatly improved the study. I thank Wendy Lynn Wendt for editing the manuscript. This research was supported by a Smithsonian Fellowship and by a Grant-in-Aid of Research from Sigma Xi to Dean E. Wendt. This paper is contribution \#448 to the Smithsonian Marine Station at Fort Pierce, Fort Pierce, Florida.

\section{Literature Cited}

Audo, M. C., T. M. Mann, T. L. Polk, C. M. Loudenslager, W. J. Diehl, and R. Altig. 1995. Food deprivation during different periods of tadpole (Hyla chrysoscelis) ontogeny affects metamorphic performance differently. Oecologia 103: 518-522. 
Aymes, Y. 1956. Croissance phototropique chez les Bryozoaires du genre Bugula. C. R. Hebd. Seances Acad. Sci. 242: 1237-1238.

Best, M. A., and J. A. Thorpe. 1986. Effects of food concentration on feeding current velocity in six species of manine Bryozod. Mar. Biol. 93: 255-262.

Best, M. A., and J. A. Thorpe. 1996. The effect of suspended particulate matter (silt) on the feeding activity of the intertidal ctenostomate bryozoan Flutrellidra hispida (Fabricius). Pp. 39-45 in Bryozoa in Space and Time, D. P. Gordon, A. M. Smith, and J. A. Grant-Mackie, eds. Colorographic International, Wellington, New Zealand.

Buss, L. W. 1979. Bryozoan overgrowth interaction-the interdependence of competition for space and food. Nature 281: 475-477.

Chia, F.-S. 1989. Differential larval settlement of benthic marine invertebrates. Pp. 3-12 in Reproduction, Genetics, and Distribution of Marine Organisms, J. S. Ryland and P. A. Tyler, eds. Olsen \& Olsen. Fredensborg. Denmark.

Crisp, D. J. 1984. Overview of research on marine invertebrate larvae, 1940-1980. Pp. 103-125 in Marine Biodeterioration: An Interdisciplinary Study, J. D. Costlow and R. C. Tipper, eds. Naval Institute Press, Annapolis, Maryland.

Denlinger, D. L. 1981. Basis for a skewed sex ratio in diapausedestined flesh flies. Evolution 34: 1247-1248.

Ebert, T. A., and M. P. Russell. 1994. Allometry and model II nonlinear regression. J. Theor. Biol. 168: 367-372.

Hadfield, M. G. 1978. Metamorphosis in marine molluscan larvae: an analysis of stimulus and response. Pp. 165175 in Settlement and Metamorphosis of Marine Invertebrate Larvae, F.-S. Chia and M. E. Rice, eds. Elsevier North-Holland, New York.

Havenhand, J. N. 1995. Evolutionary ecology of larval types. Pp. 79-122 in Ecology of Marine Invertebrate Larvae, L. R. McEdward, cd. CRC Press, Boca Raton, Florida.

Highsmith, R. C., and R. B. Emlet. 1986. Delayed metamorphosis: effect on growth and survival of juvenile sand dollars (Echinoidea: Clypeasteroida). Bull. Mar. Sci. 39: 347-361.

Hunter, E., and N. Fusetani. 1996. Studies of the effects of larval swimming time on settlement, metamorphosis, and post-larval development of Bugula neritina (Cheilostomatida). Pp. 139-148 in Bryozoa in Space and Time, D. P. Gordon. A. M. Smith, and J. A. GrantMackie, eds. Colorographic International, Wellington, New Zealand.

Hurlbut, C. J. 1993. The adaptive value of larval behavior of a colonial ascidian. Mar. Biol. 115: 253-262.

McCormick, M. I., and B. W. Molony. 1992. Effects of feeding history on the growth characteristics of a reef fish at settlement. Mar. Biol. 114: $165-173$.

McDougall, K. D. 1943. Sessile marine invertebrates at Beaufort, North Carolina. Ecol. Monogr. 13: 321-374.

Morgan, S. G. 1995. Life and death in the plankton: larval mortality and adaptation. Pp. 279321 in Ecology of Marine Invertebrate Larvae, L. R. McEdward, ed. CRC Press, Boca Raton, Florida.

Olson, R. R. 1983. Ascidian-Prochloron symbiosis: the role of larval photoadaptation in midday larval release and settlement. Biol. Bull. 165: $221-240$.

Orellena, M. R., and J. M. Cancino. 1991. The effects of delaying larval settlement on metamorphosis and early colonial growth in Celleporella hyalina (Bryozoa: Cheilostomata). Pp. 309-316 in Bryozoa Living and Fossil, F.P. Bigley, ed. Bull. Soc. Sci. Nat. Quest. Fr., Mém. HS1. Saint-Herblain, Nantes, France.

Nielsen, C. 1981. On morphology and reproduction of Hippodiplosia insculpta and Fenestrulina malusii (Bryozoa, Cheilostomata). Ophelia 20: 91-125.

Palumbi, S. R. 1994. Genetic divergence, reproductive isolation, and marine speciation. Annu. Rev. Ecol. Syst. 25: 547-572.
Pawlik, J. R. 1992. Chemical ecology of marine invertebrates Oceanogr. Mar. Biol. Annu. Rev. 30: 273-335.

Pechenik, J. A. 1990. Delayed metamorphosis of benthic marine invertebrates: Does it occur? Is there a price to pay? Ophelia 32: 63 94

Pechenik, J. A., and T. R. Cerulli. 1991. Influence of delayed metamorphosis on survival, growth, and reproduction of the polychaete Capitella sp. I. J. Exp. Mar. Biol. Ecol. 151: 17-27.

Pechenik, J. A., and L. S. Eyster. 1989. Influence of delayed metamorphosis on the growth and metabolism of young Crepidula fornicata (Gastropoda) juveniles. Biol. Bull. 176: 14-24.

Pechenik, J. A., D. Rittschof, and A. R. Schmidt. 1993. Influence of delayed metamorphosis on survival and growth of juvenile barnacles Balanus amphitrite. Mar. Biol. 115: 287-294.

Pechenik, J. A., J. N. Jarret, and D. E. Wendt. Metamorphosis is not a new beginning. BioScience (in press).

Roughgarden, J., S. Gaines, and H. Possingham. 1988. Recruitment dynamics in complex life cycles. Science 241: 1460-1466.

Rumrill, S. S. 1990. Natural mortality of marine invertebrate larvae Ophelia 32: 163-198.

Ryland, J. S. 1977. Taxes and tropisms of bryozoans. Pp. 411-436 in Biology of Bryozoans, R. M. Woollacott and R. L. Zimmer, eds. Academic Press, New York.

Scheltema, R. S. 1974. Biological interactions determining larval settlement of marine invertebrates. Thalassia Jugosl. 10: 263-296.

Schneider, D. 1959. Der Aufbau der Bugula-tierstocke und seine Beeinflussung durch Aussenfaktoren. Biol. Zentbl. 78: 250-283.

Strathmann, R. R. 1985. Feeding and nonfeeding larval development and life-history evolution in marine invertebrates. Annu. Rev. Ecol. Syst. 16: $339-361$

Strathmann, R. R. 1993. Hypotheses on the origins of invertebrate larvae. Annu. Rev. Ecol. Syst. 24: 89-117.

Taylor, P. D. 1988. Major radiation of cheilostome bryozoans: triggered by the evolution of a new larval type? Hist. Biol. 1: 45-64.

Vance, R. R. 1973. On reproductive strategies in marine bottom invertebrates. Am. Nat. 107: 353-361.

Walters, L. J. 1992. Post-settlement success of the arborescent bryozoan Bugula neritina (L.): the importance of structural complexity. J. Exp. Mar. Biol. Ecol. 164: 55-71.

Walters, L. J., and D. S. Wethey. 1991. Settlement, refuges, and adult body form in colonial marine invertebrates: a field experiment. Biol. Bull. 180: $112-118$.

Wendt, D. E. 1996. Effect of larval swimming duration on success of metamorphosis and size of the ancestrular lophophore in Bugula neritina (Bryozoa). Biol. Bull. 191: 224-233.

Wendt, D. E., and R. M. Woollacott. 1995. Induction of larval settlement by $\mathrm{KCl}$ in three species of Bugula (Bryozoa). Invertebr. Biol. 114: $345-351$

Woollacott, R. M., J. A. Pechenik, and K. M. Imbalzano. 1989. Effects of duration of larval swimming period on early colony development in Bugula stolonifera (Bryozoa: Cheilostomata). Mar. Biol. 102: $57-63$.

Wray, G. A. 1995. Evolution of larvae and developmental modes. Pp. 413-448 in Ecology of Marine Invertebrate Larvae, L. R. McEdward, ed. CRC Press, Boca Raton, Florida.

Young, C. M., and F.-S. Chia. 1981. Laboratory evidence for delay of larval settlement in response to a dominant competitor. Int. $J$. Invertebr. Reprod. 3: 221-226.

Young, C. M., and F.-S. Chia. 1984. Microhabitat-associated variability in survival and growth of subtidal solitary ascidians during the first 21 days after settlement. Mar. Biol. 81: 61-68.

Young, C. M., and F.-S. Chia. 1985. An experimental test of shadow response function in ascidian tadpoles. J. Exp. Mar. Biol. Ecol. 85: $165-175$. 